\title{
Can we heal with steel and sharpen our risk prediction tools in obstructive hypertrophic cardiomyopathy?
}

John Lynn Jefferies, MD, MPH, and Samuel G. Wittekind, MD

From the Heart Institute, Cincinnati Children's Hospital Medical Center, Cincinnati, Ohio.

Disclosures: Authors have nothing to disclose with regard to commercial support.

Received for publication March 22, 2018; accepted for publication March 27, 2018; available ahead of print April $22,2018$.

Address for reprints: John Lynn Jefferies, MD, MPH, The Heart Institute, Cincinnati Children's Hospital Medical

Center, 3333 Burnet Ave, MLC 2003, Cincinnati, OH 45229 (E-mail: john.jefferies@ cchmc.org).

J Thorac Cardiovasc Surg 2018;156:760-1

$0022-5223 / \$ 36.00$

Copyright (C) 2018 by The American Association for Thoracic Surgery

https://doi.org/10.1016/j.jtcvs.2018.03.103

The adoption of clinical guidelines for risk assessment and prevention of sudden cardiac death (SCD) in hypertrophic cardiomyopathy (HCM) has done much to advance the field. ${ }^{1,2}$ HCM is now a contemporary treatable disease, and many lives have been saved by the prudent use of implantable cardioverter defibrillators (ICDs) in high-risk patients. There is growing evidence, however, that the current risk prediction tools are too blunt and do not take into account important clinical variables that affect real-world outcomes. 3,4

In this issue of the Journal, Desai and colleagues ${ }^{5}$ sought to evaluate the prognostic utility of both the European Society of Cardiology (ESC) SCD risk score and the American College of Cardiology and American Heart Association (ACC/AHA) SCD risk factors and to identify other potential modulators of SCD risk in adult patients with obstructive HCM. The authors ${ }^{5}$ studied 1809 consecutive patients ( $50 \pm 14$ years old; $63 \%$ male) with obstructive HCM and risk stratified them according to recommendations from the $\mathrm{ACC} / \mathrm{AHA}$ guidelines and the 5-year SCD risk scoring system developed by the ESC. ${ }^{1,2}$ The end points for the study included surgical myectomy and a composite end point of SCD or appropriate ICD discharge. According to ACC/AHA criteria, $65 \%$ had 0 major risk factors, $26 \%$ had 1 , and $8 \%$ had 2 or more. According to the ESC scoring system, 65\% had low $(<4 \%)$ 5-year risk, $28 \%$ had intermediate $(4 \%-6 \%)$ 5-year risk, and $17 \%$ had high $(>6 \%)$ 5-year risk. At $8.8 \pm 4$ years of follow-up, 169 subjects met the composite end point, with 154 of these being cases of SCD. The authors $^{5}$ demonstrated that there were in fact similar numbers of composite events $(4.6 \%-5 \%)$ across the 3 groups despite the range of "expected" event rates being much broader $(2.5 \%-9 \%)$. Most of the events within 5 years occurred in the groups that would be considered at low risk by both scoring systems. Myectomy was performed in 1160 cases $(64 \%)$, and 361 subjects $(20 \%)$ had atrial fibrillation. In multivariate analysis, myectomy was associated with

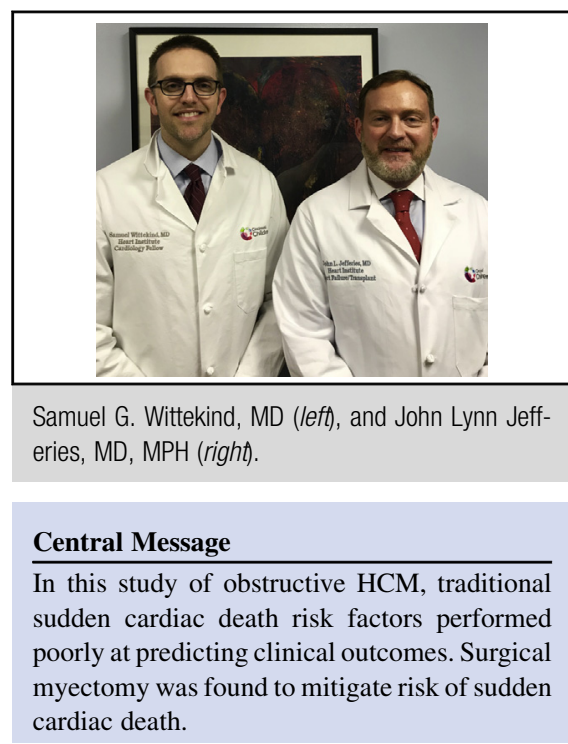

See Article page 750.

See Editorial page 748 .

lower long-term risk, whereas the ESC SCD risk score was not. Atrial fibrillation also added prognostic information in the analysis (subhazard ratio, 1.52; 95\% confidence interval, 1.09-2.035).

These findings underscore the fact that the current strategies for risk stratification of SCD in obstructive HCM have significant limitations and do not adequately predict outcomes in all populations. Desai and colleagues are to be applauded for their skepticism of the guidelines and their use of advanced statistics to lay bare these limitations. In addition, this unique patient population from a tertiary surgical center allowed these investigators to examine the effect of myectomy on long-term SCD risk. On the basis of their findings, a strong case is made for including myectomy in future risk scores. Limitations of the study include its single-center, retrospective nature and associated selection bias, lack of blinding, and risk of outcome misclassification. It is also of note that only middle-aged patients were included, despite the fact that HCM remains a leading cause of SCD in adolescents and young adults. ${ }^{6,7}$ Indeed, HCM is the most common cause of SCD in young, competitive athletes. ${ }^{8}$ Although the natural history of HCM in youth may differ from that in older adults, high-risk young patients can benefit from 
ICDs. A recent study that examined a multinational registry of 224 pediatric (mean age 14.5 years) patients with HCM who had ICDs implanted for SCD prevention in accordance with the aforementioned adult criteria demonstrated an appropriate ICD intervention rate of $4.5 \%$ per year overall, $14.0 \%$ per year for secondary prevention, and $3.1 \%$ per year for primary prevention. ${ }^{9}$ In a striking parallel with the study of Desai and colleagues, ${ }^{5}$ the appropriate ICD discharge rate was the same in those pediatric patients with 1,2 , or 3 or more traditional risk factors at implantation for primary prevention. ${ }^{9}$ It should be noted that the rate of transvenous ICD complications in this age group is higher than in adults, so the threshold to implant may be higher. A final limitation of this study of Desai and colleagues ${ }^{5}$ is that no genotypic or cardiac magnetic resonance imaging variables were included in the study, but these markers are currently used by many centers in clinical practice. ${ }^{10-12}$

This study by Desai and colleagues ${ }^{5}$ highlights the urgent need for advanced risk prediction tools in the heterogeneous population of patients with HCM. The development of these tools will require multicenter registries that collect a multitude of clinical details, including cardiac magnetic resonance imaging, genetic, and biomarker data, and then track patient outcomes for many years. Examples of this trend include the large, multicenter HCMR-Novel Markers of Prognosis in Hypertrophic Cardiomyopathy trial ${ }^{13}$ referenced by the authors ${ }^{5}$ and the Sarcomeric Human Cardiomyopathy Registry (SHaRe), to which our institution contributes. ${ }^{14}$ This "deep phenotyping" approach holds the promise of tailored therapy that can maximize benefit and minimize risk in individual patients with HCM.

\section{References}

1. Gersh BJ, Maron BJ, Bonow RO, Dearani JA, Fifer MA, Link MS, et al; American College of Cardiology Foundation/American Heart Association task force on practice guidelines. $2011 \mathrm{ACCF} / \mathrm{AHA}$ guideline for the diagnosis and treatment of hypertrophic cardiomyopathy: a report of the American College of Cardiology Foundation/American Heart Association task force on practice guidelines. Developed in collaboration with the American Association for Thoracic Surgery, American Society of Echocardiography,
American Society of Nuclear Cardiology, Heart Failure Society of America, Heart Rhythm Society, Society for Cardiovascular Angiography and Interventions, and Society of Thoracic Surgeons. J Am Coll Cardiol. 2011;58: e212-60.

2. Elliott PM, Anastasakis A, Borger MA, Borggrefe M, Cecchi F, Charron P, et al. 2014 ESC guidelines on diagnosis and management of hypertrophic cardiomyopathy: the task force for the diagnosis and management of hypertrophic cardiomyopathy of the European Society of Cardiology (ESC). Eur Heart J. 2014;35: 2733-79.

3. Maron BJ, Casey SA, Chan RH, Garberich RF, Rowin EJ, Maron MS. Independent assessment of the European Society of Cardiology sudden death risk model for hypertrophic cardiomyopathy. Am J Cardiol. 2015;116: 757-64.

4. O’Mahony C, Jichi F, Pavlou M, Monserrat L, Anastasakis A, Rapezzi C, et al; Hypertrophic Cardiomyopathy Outcomes Investigators. A novel clinical risk prediction model for sudden cardiac death in hypertrophic cardiomyopathy (HCM risk-SCD). Eur Heart J. 2014;35:2010-20.

5. Desai MY, Smedira NG, Dhillon A, Masri A, Wazni O, Kanj M, et al. Prediction of sudden death risk in obstructive hypertrophic cardiomyopathy: potential for refinement of current criteria. J Thorac Cardiovasc Surg. 2018;156:750-9.

6. Bagnall RD, Weintraub RG, Ingles J, Duflou J, Yeates L, Lam L, et al. A prospective study of sudden cardiac death among children and young adults. $N$ Engl $J$ Med. 2016;374:2441-52.

7. Meyer L, Stubbs B, Fahrenbruch C, Maeda C, Harmon K, Eisenberg M, et al. Incidence, causes, and survival trends from cardiovascular-related sudden cardiac arrest in children and young adults 0 to 35 years of age: a 30-year review. Circulation. 2012;126:1363-72.

8. Maron BJ, Doerer JJ, Haas TS, Tierney DM, Mueller FO. Sudden deaths in young competitive athletes: analysis of 1866 deaths in the United States, 1980-2006. Circulation. 2009;119:1085-92.

9. Maron BJ, Spirito P, Ackerman MJ, Casey SA, Semsarian C, Estes NA III, et al. Prevention of sudden cardiac death with implantable cardioverter-defibrillators in children and adolescents with hypertrophic cardiomyopathy. J Am Coll Cardiol. 2013;61:1527-35.

10. Sabater-Molina M, Pérez-Sánchez I, Hernández Del Rincón JP, Gimeno JR. Genetics of hypertrophic cardiomyopathy: a review of current state. Clin Genet. 2018;93:3-14.

11. Maron BJ, Maron MS. LGE means better selection of HCM patients for primary prevention implantable defibrillators. JACC Cardiovasc Imaging. 2016;9: 1403-6.

12. Chan RH, Maron BJ, Olivotto I, Pencina MJ, Assenza GE, Haas T, et al. Prog nostic value of quantitative contrast-enhanced cardiovascular magnetic resonance for the evaluation of sudden death risk in patients with hypertrophic cardiomyopathy. Circulation. 2014;130:484-95.

13. Kramer CM, Appelbaum E, Desai MY, Desvigne-Nickens P, DiMarco JP, Friedrich MG, et al. Hypertrophic cardiomyopathy registry: the rationale and design of an international, observational study of hypertrophic cardiomyopathy. Am Heart J. 2015; 170:223-30.

14. Furqan A, Arscott P, Girolami F, Cirino AL, Michels M, Day SM, et al; SHaRe Consortium. Care in specialized centers and data sharing increase agreement in hypertrophic cardiomyopathy genetic test interpretation. Circ Cardiovasc Genet. $2017 ; 10$. 